\section{HEVIVEO $0=0 \cap 89996$ $8 \mathrm{TI}$}

Computer Modeling of Electromagnetic Fields and Fluid Flows for Edge Containment in Continuous Casting

F. C. Chang and John R. Hull

Energy Technology Division

Argonne National Laboratory

9700 S. Cass Avenue

Argonne, IL 60439

The submitted manuscript has been authorized by a contract of the U.S. Government under contract No. W-31-109-ENG-38. Accordingly, the U.S. Government retains a non-exclusive, royalty-free license to publish or reproduce the published form of this contribution, or allow others to do so, for U.S. Government purposes.

Submitted to the 1996 ASME Pressure Vessel and Piping Conference, Montreal, Canada, July 21-26, 1996.

*Work at Argonne National Laboratory was supported by the U.S. Dept. of Energy, under contract No. W-31-109-ENG-38. 


\section{DISCLAMMER}

Portions of this document may be illegible in electronic image products. Images-are produced from the best available original document. 


\title{
Computer Modeling of Electromagnetic Fields and Fluid Flows for Edge Containment in Continuous Casting
}

\author{
F. C. Chang and John R. Hull \\ Argonne National Laboratory

\section{Y. H. Wang and Kenneth E. Blazek \\ Inland Steel Company}

A computer model was developed to predict eddy currents and fluid flows in molten steel. The model was verified by comparing predictions with experimental results of liquid-metal containment and fluid flow in electromagnetic (EM) edge dams (EMDs) designed at Inland Steel for twin-roll casting. The model can optimize the EMD design so it is suitable for application, and minimize expensive, time-consuming full-scale testing.

Numerical simulation was performed by coupling a three-dimensional (3-D) finite-element EM code (ELEKTRA) and a 3-D finite-difference fluids code (CaPS-EM) to solve heat transfer, fluid flow, and turbulence transport in a casting process that involves EM fields. ELEKTRA is able to predict the eddy-current distribution and the electromagnetic forces in complex geometries. CaPS-EM is capable of modeling fluid flows with free surfaces. Results of the numerical simulation compared well with measurements obtained from a static test. 


\section{INTRODUCTION}

Steel sheets are widely used in the automotive and appliance industries. Most steel sheets are now made by continuous casting of 50 - to 300 -mm-thick slabs, followed by hot rolling to reduce the thickness to $\approx 2.5 \mathrm{~mm}$, and then by cold rolling to the final thickness. The configuration of traditional slab casting is shown in Figure 1. The hot-rolling stage is very capital-and energyintensive, adding significantly to the cost of the finished product. Industry has an urgent need to develop its capability to cast relatively thin sheets of steel. If thin sheets could be cast, the entire hot-rolling portion of the process could be eliminated. The cost savings would give the sheet product an enormous economic advantage over products made by competing methods.

Twin-roll casting has been used for the production of wide, thin aluminum strips. Several twin-roll processes are used to cast strips that are $2-5 \mathrm{~mm}$ thick and $1500-2000 \mathrm{~mm}$ wide [1-5]. This technique for casting thin strip traditionally uses some type of ceramic material at the ends of counter-rotating rolls to contain the molten metal pool, as shown in Figure 2. Ceramic dams only endure for a short period of time and are susceptible to erosion and breakage. They also are sites on which the molten metal can solidify and this solidified material can become attached to the strip being formed and thus alter the roll gap spacing, and hence the thickness of the cast product and the surface temperature. These alternations can lead to surface defects, variation in product thickness, leakage of liquid steel from the caster, and even strand breakage and liquid steel breakouts.

Magnetics is increasingly being used in a broad range of metallurgical applications. These range from relatively mature applications such as the electromagnetic (EM) mold for casting aluminum [6] to emerging or proposed applications such as levitation and/or confinement in the entry region between the tundish and a horizontal casting mold, edge confinement [7] and control [8] within a strip or plate caster, and control of shape (e.g., thickness) to near final form specifications [9]. In virtually all such applications, an alternating EM field is used to induce current to flow within the molten metal to create the desired confinement forces. The confinement forces work against a static head that, in many applications, is primarily gravitational in origin.

Use of the EM field will play a major role in the evolution of the steel industry [10-14]. No contact is made with the steel; defects can be minimized, and product quality can be improved. Many product quality problems are related to mold and air-gap formation, and to interaction of the ingot shell and liquid core. These problems could be eliminated by moldless casting, wherein an EM field supports the liquid metal until it enters the direct-quench zone. The application of EM edge dams (EMDs) in twin-roll casting (Figure 3) can bypass fundamental problems of ceramic 
solid dams and makes economic sense [15,16]. In other words, if the EMD concept is successful, all of the problems associated with ceramic edge containment could be eliminated and the possibility of successfully developing a twin-roll strip casting process for steel would be greatly increased Application of EM fields in twin-roll casting is a complicated process that involves interaction among electric, magnetic, thermal, mechanical, and metallurgical phenomena. Therefore, modeling is needed to help optimize the performance of products, enhance their value, get them to the marketplace sooner, and gain competitive advantages for business and industry.

Argonne National Laboratory (ANL) and Inland Steel Company have worked together to develop a three-dimensional (3-D) computer model that can predict fluid flows and eddy currents in EMDs for twin-roll casting. Numerical simulations were performed to compute the EM force and fluid flow by coupling the finite-element EM code ELEKTRA and the finite-difference casting process magnetohydrodynamic code CaPS-EM. ELEKTRA solves 3-D time-varying EM field equations and predicts the induced eddy currents and EM forces. The time variation can be either transient or steady-state ac. CaPS-EM provides an efficient solution of transient heat conduction within the metal and between the metal and the mold and computes the profile of the free surface [17]. The computed 3-D magnetic fields and induced current densities in ELEKTRA are used as input for flow-field computations in CaPS-EM. The model developed by ANL and Inland Steel Company involves solutions of the Maxwell equations, the Navier-Stokes equations, and the transport equations for the turbulence kinetic energy $\mathbf{k}$ and its rate of dissipation $\varepsilon$. Turbulent flow is included to describe recirculating electromagnetically induced flows, and control of turbulent flow in the liquid metal is an efficient method to improve performance of the EM system. The model utilizes the design data and operating parameters of a static test rig of an industrial twin-roll caster at $4.4 \mathrm{kHz}$ to compute transient fluid flows. 


\section{MATHEMATICAL MODEL AND NUMERICAL PROCEDURE}

In this study, fluid flow of liquid metal with a free surface under EM force was investigated numerically. The volume fraction method was introduced to treat the free surface, and the magnetic potential was used for eddy-current analysis. The shape of the free surface is governed primarily by the balance of EM pressures against pressures due to gravity. Transfer of momentum due to both flow of molten metal and turbulence may also be of critical importance. Quantitative mathematical representation of this system involves the induced current, the EM field, the EM force, and the resulting fluid flow. These steps may be conveniently divided into EM calculations and fluid-flow computations.

The following assumptions and simplifications are made in the mathematical model:

- All flows are assumed to be isotropic and at steady state.

- Fluid flow due to causes other than EM action (e.g., pouring stream) is not included in the simulation.

- Time-averaged values of the EM forces are appropriate for fluid-flow calculations.

\subsection{Electromagnetic Equations}

ELEKTRA uses a combination of vector and scalar magnetic potentials to model time-varying EM fields. Vector potentials are used in conducting media, and scalar potentials are used elsewhere. In time-varying fields, the currents induced in conducting volumes are some of the unknowns in the system. Therefore, their fields cannot be evaluated by simply performing an integration. Inside the conducting volumes, the field representation must include a rotational component. ELEKTRA combines the efficient total-and-reduced scalar potential method for nonconducting volumes with an algorithm that uses a vector potential in the conducting volumes.

In a low-frequency time-varying magnetic field, when the dimensions of the objects in the space are small compared with the wavelengths of the fields, the magnetic and electric fields are related by the low-frequency limit of Maxwell's equations:

Magnetic flux density:

$$
\vec{\nabla} \cdot \overrightarrow{\mathrm{B}}=0
$$

Ampere's Law:

$$
\overrightarrow{\mathrm{J}}=\vec{\nabla} \times \overrightarrow{\mathrm{H}}
$$

Faraday's Law:

$$
\bar{\nabla} \times \overline{\mathrm{E}}=-\partial \overline{\mathrm{B}} / \partial \mathrm{t}
$$


Ohm's Law:

$$
\vec{J}=\sigma(\vec{E}+\vec{U} \times \vec{B})
$$

where $\sigma$ is the electrical conductivity, $\overline{\mathrm{B}}$ is the magnetic flux density, $\overline{\mathrm{E}}$ is the electric field strength, $\overline{\mathrm{H}}$ is the magnetic field strength, and $\overrightarrow{\mathrm{J}}$ is the current density. Once the current distribution and the vector potential are known, the magnetic field is readily calculated and one may then obtain the EM force $\vec{F}$ by using the relationship

$$
\overline{\mathrm{F}}=\overline{\mathrm{J}} \times \overline{\mathrm{B}}
$$

\subsection{Fluid Flow Equations [17,18]}

The conservation equations of continuity, motion, and energy in CaPS are developed by the mass, momentum, and energy balance, respectively, over a control volume, i.e.,

$$
\frac{\partial \rho}{\partial \mathrm{t}}+\frac{\partial\left(\rho \mathrm{U}_{\mathrm{i}}\right)}{\partial \mathrm{x}_{\mathrm{i}}}=0
$$

Equation 6 indicates that the rate of mass accumulation is the difference between the rate of mass into and mass out of the control volume, i.e.,

$$
\rho \frac{\partial \mathrm{U}_{\mathrm{i}}}{\partial \mathrm{t}}+\rho \mathrm{U}_{\mathrm{j}} \frac{\partial \mathrm{U}_{\mathrm{i}}}{\partial \mathrm{x}_{\mathrm{j}}}=\frac{\partial}{\partial \mathrm{x}_{\mathrm{j}}}\left[\left(\mu_{\ell}+\mu_{\mathrm{t}}\right) \frac{\partial \mathrm{U}_{\mathrm{i}}}{\partial \mathrm{x}_{\mathrm{j}}}\right]-\frac{\partial \mathrm{p}}{\partial \mathrm{x}_{\mathrm{i}}}+\rho \mathrm{g}_{\mathrm{i}}+\varepsilon_{\mathrm{ijk}} \mathrm{J}_{\mathrm{j}} \mathrm{B}_{\mathrm{k}} .
$$

In Eq. 7, the terms on left-hand side indicate the rate of increase of momentum. The terms on the right-hand side are the rate of momentum gain by convection, the pressure force on an element, the rate of momentum gain by viscous transfer, the gravitational force on an element, and the EM force on an element, respectively.

\subsection{Turbulence Model}

In the bulk of the liquid, the $\mathrm{k}-\varepsilon$ model is used. The transport equations that describe the time and space distributions of turbulence kinetic energy $k$ and its rate of dissipation $\varepsilon$ (Eqs. 8 and 9) are given in terms of production, buoyancy, dissipation, and diffusion. The EM effect on turbulence is implied by the last term of Eq. 8 [19].

$$
\begin{aligned}
& \rho \frac{\partial \mathrm{k}}{\partial \mathrm{t}}+\rho \mathrm{U}_{\mathrm{j}} \frac{\partial \mathrm{k}}{\partial \mathrm{x}_{\mathrm{j}}}=\mathrm{P}_{\mathrm{k}}+\mathrm{G}_{\mathrm{k}}-\rho \varepsilon+\frac{\partial}{\partial \mathrm{x}_{\mathrm{j}}}\left[\left(\frac{\mu_{\mathrm{t}}}{\sigma_{\mathrm{k}}}+\mu_{\ell}\right) \frac{\partial \mathrm{k}}{\partial \mathrm{x}_{\mathrm{j}}}\right]-\frac{4}{3} \mathrm{c}_{\mathrm{MHD}} \sigma \mathrm{k} \mathrm{B}_{\mathrm{j}} \mathrm{B}_{\mathrm{j}} \\
& \rho \frac{\partial \varepsilon}{\partial \mathrm{t}}+\rho \mathrm{U}_{\mathrm{j}} \frac{\partial \varepsilon}{\partial \mathrm{x}_{\mathrm{j}}}=\mathrm{c}_{1 \varepsilon} \frac{\varepsilon}{\mathrm{k}}\left(\mathrm{P}_{\mathrm{k}}+\mathrm{G}_{\mathrm{k}}\right)-\mathrm{c}_{2 \varepsilon} \rho \frac{\varepsilon^{2}}{\mathrm{k}}+\frac{\partial}{\partial \mathrm{x}_{\mathrm{j}}}\left[\left(\frac{\mu_{\mathrm{t}}}{\sigma_{\varepsilon}}+\mu_{\ell}\right) \frac{\partial \varepsilon}{\partial \mathrm{x}_{\mathrm{j}}}\right] .
\end{aligned}
$$


In Eqs. 8 and $9, P_{k}$ and $G_{k}$ are defined by Ref. 20 as follows:

$$
\mathrm{P}_{\mathrm{k}}=\mu_{\mathrm{eff}}\left[\frac{\partial \mathrm{U}_{\mathrm{i}}}{\partial \mathrm{x}_{\mathrm{j}}}\left(\frac{\partial \mathrm{U}_{\mathrm{i}}}{\partial \mathrm{x}_{\mathrm{j}}}+\frac{\partial \mathrm{U}_{\mathrm{j}}}{\partial \mathrm{x}_{\mathrm{i}}}\right)\right]
$$

and

$$
\mathrm{G}_{\mathrm{k}}=-\frac{\mu_{\mathrm{t}}}{\rho \sigma_{\mathrm{h}}} \frac{\partial \rho}{\partial \mathrm{T}}\left(\frac{\partial \mathrm{T}}{\partial \mathrm{x}_{\mathrm{j}}} \mathrm{g}_{\mathrm{j}}\right)
$$

Here, $P_{k}$ is the source term due to mean shear and $G_{k}$ is the source term due to thermal buoyancy. $\sigma_{\mathrm{h}}(=0.9)$ is the turbulence Prandtl number, used to calculate turbulent conductivity, and $\sigma_{\mathrm{k}}(=1.0)$ is the turbulence Prandtl number for k. $\sigma_{\varepsilon}(=1.3)$ is the turbulence Prandtl number for $\varepsilon, c_{1 \varepsilon}$ $(=1.44)$ is the coefficient of turbulence production, and $c_{2 \varepsilon}(=1.92)$ is the coefficient for decay-ofgrid turbulence. The effective viscosity $\mu_{\mathrm{eff}}\left(=\mu_{\ell}+\mu_{\mathrm{t}}\right)$ is the sum of laminar and turbulent viscosities.

In the immediate vicinity of a solid wall, the values of turbulence properties vary significantly. Therefore, the wall function treatment is applied to predict the correct values of momentum flux, energy flux, and gradient of $\mathrm{k}$ and $\varepsilon$. Figure 4 shows the two-layer wall function model [20] used in the simulation. When $y_{p}>y_{\ell}$, the first node is in the fully turbulent zone and one has

$$
\mathrm{k}_{\mathrm{p}}=\mathrm{u}^{*^{2}} / \sqrt{\mathrm{c}_{\mu}}
$$

and

$$
\varepsilon_{\mathrm{p}}=\mathrm{u}^{* 3} /\left(\mathrm{Ky}_{\mathrm{p}}\right)
$$

When $y_{p} \leq y_{\ell}$, the node $P$ is in the laminar sublayer and one has

$$
\mathrm{k}_{\mathrm{p}}=\mathrm{u}^{* 2}\left(\mathrm{y}_{\mathrm{p}} / \mathrm{y}_{\ell}\right) / \sqrt{\mathrm{c}_{\mu}}
$$

and

$$
\varepsilon_{\mathrm{p}}=\mathrm{u}^{* 3} /\left(\mathrm{K}_{\ell}\right)
$$

where $c_{\mu}=0.09, \mathrm{~K}(=0.42)$ is the von Karman constant and $\mathrm{E}(=9.0)$ is determined from the roughness of the wall. 


\subsection{Data Transfer from ELEKTRA to CaPS}

ELEKTRA solves the 3-D time-varying magnetic field equations. When the time variation is alternating (steady state), all quantities in ELEKTRA are complex phasors and can be expressed in the form

$$
X=X_{\text {avg }} \cos (\omega t-\Theta)
$$

Consequently, after performing dot or cross products with these quantities, the computations come out in the form

$$
Y=Z \cos (2 \omega t-\Psi)
$$

To calculate the average values of $\varepsilon_{i j k} \mathrm{~J}_{j} B_{k}$ and $B_{j} B_{j}$ per cycle in Eqs. 7 and 8 from the ELEKTRA postprocessor, it is necessary to output the real part (ac time angle $=0^{\circ}$ ) and imaginary part (ac time angle $=90^{\circ}$ ) of the quantity in separate tables and average the value in a separate independent code. The computations are evaluated as follows:

Set ac time angle $=0^{\circ}$ and create the table

$$
\begin{aligned}
& B_{1}^{2}=B_{x}^{2}+B_{y}^{2}+B_{z}^{2} \\
& F_{x 1}=J_{y} B_{z}-J_{z} B_{y} \\
& F_{y 1}=J_{z} B_{x}-J_{x} B_{z} \\
& F_{z 1}=J_{x} B_{y}-J_{y} B_{x}
\end{aligned}
$$

Set ac time angle $=90^{\circ}$ and create the table

$$
\begin{aligned}
& B_{2}^{2}=B_{x}^{2}+B_{y}^{2}+B_{z}^{2} \\
& F_{x 2}=J_{y} B_{z}-J_{z} B_{y} \\
& F_{y 2}=J_{z} B_{x}-J_{x} B_{z} \\
& F_{z 2}=J_{x} B_{y}-J_{y} B_{x},
\end{aligned}
$$

Average values to obtain

$$
\begin{aligned}
& \overrightarrow{\mathrm{B}} \cdot \overrightarrow{\mathrm{B}}=\left(\mathrm{B}_{1}^{2}+\mathrm{B}_{2}^{2}\right) / 2 \\
& \mathrm{~F}_{\mathrm{x}}=\left(\mathrm{F}_{\mathrm{x} 1}+\mathrm{F}_{\mathrm{x} 2}\right) / 2 \\
& \mathrm{~F}_{\mathrm{y}}=\left(\mathrm{F}_{\mathrm{y} 1}+\mathrm{F}_{\mathrm{y} 2}\right) / 2 \\
& \mathrm{~F}_{\mathrm{z}}=\left(\mathrm{F}_{\mathrm{z} 1}+\mathrm{F}_{\mathrm{z} 2}\right) / 2
\end{aligned}
$$




\subsection{Potentials and Boundary Conditions}

In ELEKTRA, the choice of potential type in each region depends on the properties of the region. Either reduced potential or total potential can be used in current-free regions, whereas vector potential must be used in eddy-current regions. In this application, reduced potential is used in the air-region, total potential is used for lamination material, and vector potential is applied to liquid Indalloy, copper shield, roller, carbon steel tube, and carbon steel plate.

The boundary conditions of thermal hydraulics used in this study are symmetry about the center line, no slip at the solid surfaces introduced through wall functions, free surface at the top of the liquid metal, and free surface at the interface between the liquid metal and the air gap. These boundary conditions are not thought to introduce a serious error that will affect the general nature of the system. For the isothermal flow of liquid metal, heat transfer will not occur between the liquid Indalloy and the ambient air, and the energy equation is not solved.

\section{SYSTEM LAYOUT}

The basic concept for the EMD to provide containment in twin-roll casting is to create a primary time-varying magnetic field that penetrates a passive conductor (the liquid metal to be contained). As the time-varying field changes, an EM force is generated in the plane at right angles to the direction of the changing flux, resulting in a perpendicular current flow within the liquid metal. The induced current interacts with the primary magnetic field to create a body force (Lorentz force) on the liquid metal that repels the conductor away from the source of the primary field and contains the molten metal. The body force on the liquid metal is the vector cross product of the induced current density and the magnetic flux density. The design problem reduces to that of placing a confinement coil or coils so that a desired free-surface shape can be obtained or metal can be confined against a specified static head.

Figure 5 displays a schematic arrangement of one EMD in a static test rig configuration, labeled the "Proximity type EMD" [15,16]. A copper conductor is placed parallel to the plane of the desired containment. A large ac current passes through the conductor and is concentrated on the face of the conductor closest to the liquid metal because of the proximity of the conductor to the liquid metal. The ac vertical current creates a horizontal magnetic field. The liquid metal that is to be contained interacts with the magnetic field, and the containment forces are generated. These forces support the liquid metal until it passes the kissing point of the rolls. In this design, a highpermeability lamination material that surrounds the conductor enhances this effect and concentrates the magnetic flux density. The size of the air gap inside the lamination material decreases from 
bottom (nip) to top and is used to adjust the magnetic field. The copper shield surrounding the lamination material confines the magnetic field. The main parameters of the computational data are summarized in Table 1. 
Table I. Parameters of computational setup

\begin{tabular}{|c|c|}
\hline Parameter & Values \\
\hline \multicolumn{2}{|l|}{ Magnetic coils } \\
\hline No phases & 1 \\
\hline Operating current $(\mathrm{kA})$ & 13 \\
\hline Frequency $(\mathrm{kHz})$ & 4.4 \\
\hline \multicolumn{2}{|l|}{ EMD geometry } \\
\hline Air gap between EMD and liquid metal (m) & 0.005 \\
\hline Dimension of twin-roll nip (m) & 0.01 \\
\hline Diameter of roller $(\mathrm{m})$ & 1.2 \\
\hline Height of liquid metal containment $(\mathrm{m})$ & 0.25 \\
\hline \multicolumn{2}{|l|}{ Properties } \\
\hline \multicolumn{2}{|l|}{ Liquid metal (Indalloy) } \\
\hline Density $\left(\mathrm{kg} / \mathrm{m}^{3}\right)$ & 8440 \\
\hline Electric conductivity (S/m) & $1.41 \mathrm{e}+6$ \\
\hline Kinematic viscosity $\left(\mathrm{m}^{2} / \mathrm{s}\right)$ & $2.14 \mathrm{e}-3$ \\
\hline Relative permeability & 1.0 \\
\hline \multicolumn{2}{|l|}{ Copper roller } \\
\hline Electric conductivity (S/m) & $2.0 \mathrm{e}+7$ \\
\hline Relative permeability & 1.0 \\
\hline \multicolumn{2}{|l|}{ Carbon steel tube and plate } \\
\hline Electric conductivity $(\mathrm{S} / \mathrm{m})$ & $1.0 \mathrm{e}+6$ \\
\hline Relative permeability & 1000.0 \\
\hline \multicolumn{2}{|l|}{ Lamination material } \\
\hline Electric conductivity (S/m) & 0.0 \\
\hline Relative permeability & 1000.0 \\
\hline \multicolumn{2}{|l|}{ Copper shield } \\
\hline Electric conductivity $(\mathrm{S} / \mathrm{m})$ & $5.0 \mathrm{e}+7$ \\
\hline Relative permeability & 1.0 \\
\hline
\end{tabular}




\section{RESULTS AND DISCUSSION}

Figure 6 shows the magnetic flux density component $\left(B_{x}\right)$ as a function of vertical distance at the center of a $5-\mathrm{mm}$ air gap with $\mathrm{I}=3.742 \mathrm{kA}$ and $\mathrm{f}=4.231 \mathrm{kHz}$ for the EMD. Computational data are compared with experimental data at several selected locations (at the centerline and 2 and 4 $\mathrm{cm}$ to the left of the centerline) when there is no liquid metal (Indalloy) in the containment. The computational results agree well with the measured data along the vertical distance in the air gap.

Table 2 shows the stored energy (integral $\mathrm{B} \cdot \mathrm{H} / 2 \mathrm{dv}$ ) and power loss (integral $\mathrm{J} * 2 / \sigma \mathrm{dv}$ ) of the materials used in EMD applications. The percentage (\%) of each material is the ratio to all the materials (five materials in this case). It can be seen from Table 2 that most of power is lost in the carbon steel tube (60.6\% for stored energy and $94.6 \%$ for power loss) because of its high permeability (Table 1). With high energy consumption and high Joule heating in the carbon steel tube, cooling water is required in this design (Figure 5). However, even with this disadvantage, carbon steel is still used because it can confine the magnetic flux and provide a uniform magnetic field that crosses the liquid metal because of its high permeability and small skin depth. Because most of the magnetic flux density is confined within the skin depth of the carbon steel tube, only a little magnetic flux penetrates into the carbon steel plate and induces low stored energy and power loss. The copper roller and copper shield have low stored energy and low power loss because of their high electric conductivity and low permeability.

Table 2 Stored energy and power loss in EMD materials

\begin{tabular}{|l|c|c|}
\hline Materials & Stored Energy (\%) & Power Loss (\%) \\
\hline Copper Roller & 2.7 & 0.3 \\
\hline Carbon Steel Tube & 60.6 & 94.6 \\
\hline Carbon Steel Plate & 2.9 & 4.8 \\
\hline Lamination Material & 32.0 & 0.0 \\
\hline Copper Shield & 1.8 & 0.3 \\
\hline
\end{tabular}


Figure 7 shows the distribution of the magnetic tlux density vector at a cut plane, $15 \mathrm{~cm}$ above the nip, of the EMD $(\mathrm{I}=13 \mathrm{kA}, \mathrm{f}=4.4 \mathrm{kHz})$ in a twin-roll casting static test rig. In Figure 7, with high permeability in the lamination and low permeability in the copper shield, magnetic flux concentrates in the lamination; then crosses the air gap; locates inside the skin depths of the carbon steel tube, the carbon steel plate, and the Indalloy; and finally returns to the lamination with a closed loop. As seen. under the effect of the periodic current, the conductor generates a variable magnetic field in the system, which, in turn, gives rise to an induced current. Thus, the liquid metal is subject to EM body forces caused by the interaction of the eddy currents and the magnetic field. With these EM forces, liquid metal could be confined within the mold in the EMD application.

Figure 8 displays profiles of magnetic flux density (8a), induced eddy current (8b), and Lorentz's force (8c) in the liquid metal Indalloy at $I=13 \mathrm{kA}, f=4.4 \mathrm{kHz}$ for the EMD. Any one of these three field vectors is always perpendicular to the others. At the surface of the Indalloy, near the inductor, most of the magnetic flux density, eddy current, and magnetic forces accumulate at a short depth into the Indalloy because of the skin depth effect. The maximum values of flux density, eddy current, and force occur at the nip of the liquid metal because the distance at the nip of the liquid metal is minimal. Maximum magnetic force is necessary to overcome the maximum hydrostatic pressure at the nip. From the design point view, it is also necessary that the induced magnetic force be large enough to overcome the hydrostatic pressure of the liquid metal and to confine the liquid metal inside the container.

Figure 9 presents the free surface profile of the liquid metal Indalloy in a twin-roll casting static test rig with an EMD $(\mathrm{I}=13 \mathrm{kA}, \mathrm{f}=4.4 \mathrm{kHz})$. The volume fraction method was introduced to track the free interface between the liquid metal and the air gap. The shape of the free surface is governed primarily by the balance of EM pressures against pressures due to gravity. With the capability to predict free surface shape, the design problem reduces to that of placing a conducting coil or coils so that a desired free surface can be obtained or that metal can be confined against a specified static head.

Figure 10 displays the velocity profile of the liquid metal Indalloy under EM fields ( $I=13$ $\mathrm{kA}, \mathrm{f}=4.4 \mathrm{kHz}$ ). The circulation flow pattern is induced by EM fields and gravity, and the velocity is transported inside the liquid metal by fluid viscosity, especially by turbulence viscosity. The maximum velocity $(4.47 \mathrm{~m} / \mathrm{s})$ occurs at the nip of the liquid metal, near the inductor, because of the maximum magnetic force at that location.

Figures $11 \mathrm{a}$ and $11 \mathrm{~b}$ show the confinement of the liquid metal Indalloy for operating currents of $\mathrm{I}=13 \mathrm{kA}, \mathrm{f}=4.4 \mathrm{kHz}$, and $\mathrm{I}=18 \mathrm{kA}, \mathrm{f}=4.4 \mathrm{kHz}$, respectively, in a twin-roll casting static 
test rig. Figures $1 \mathrm{la}$ and $\mathrm{ll}$ b are the free surfice shapes observed from a vertical cut plane through the center of the liquid metal. In Figure $11 \mathrm{a}$, with $I=13 \mathrm{kA}$, the top of the pool barely touches the magnet at the locations that are close to the surface of the roller. Here, the top does not mean the height at the liquid-metal head, which is $25 \mathrm{~cm}$ above the nip, but a height $\approx 18-22 \mathrm{~cm}$ above the nip. In other words, liquid metal may touch the magnet near the roller surface at a height of $\approx 18$ $22 \mathrm{~cm}$, and above $22 \mathrm{~cm}$, it is pushed far away from the magnet. Below $18 \mathrm{~cm}$, liquid metal is well contained. In the Fig. $11 \mathrm{~b}$ with a stronger current $(I=18 \mathrm{kA})$ in the coil, liquid metal is contained everywhere. The push-back distance of liquid Indalloy from the face of the EMD under EM force is shown in Table 3 for the case when $\mathrm{I}=18 \mathrm{kA}, \mathrm{f}=4.4 \mathrm{kHz}$. The information included in Table 3 and Figures $11 \mathrm{a}$ and $11 \mathrm{~b}$ was obtained from the computer model and can be used to optimize the caster design for a commercial device.

Table 3 Computer-modeled push-back distance of liquid Indalloy from magnetic dam face when $\mathrm{I}=18 \mathrm{kA}$ and $\mathrm{f}=4.4 \mathrm{kHz}$

\begin{tabular}{|l|c|c|c|c|c|}
\hline Height above nip (cm) & 5 & 10 & 15 & 20 & 25 \\
\hline Push-back (mm) & 7.8 & 7.0 & 6.5 & 6.5 & 27 \\
\hline
\end{tabular}

\section{SUMMARY}

Numerical simulations of the EM fields and the fluid flows within liquid metal have been performed for a thin-strip twin-roll casting static test rig with an EMD that closely approximates an actual continuous casting arrangement. The coupling of a 3-D EM code (ELEKTRA) and a 3-D thermal hydraulic code (CaPS-EM) provided encouraging consistency and a reasonably accurate prediction of the flow pattern, free surface shape, and EMD containment. The model presented here demonstrates the feasibility of full-face containment by the EMD under various operating conditions.

The followup work on this research will be the development of a 3-D model for dynamic electromagnetic edge containment. The entry nozzle and rotational roller will be included in the model. A prediction of the magnetic field, eddy current, magnetic force, fluid flow, solidification, and liquid-metal containment for dynamic test rigs will be performed to optimize the design of the electromagnetic twin-roll caster. 


\section{REFERENCES}

1. Miyazawa, K., and Szekely, J., A Mathematical Model of the Splat Cooling Process Using the Twin-Roll Technique, Metallurgical Transactions A, Vol. 12A(6), 1981, pp. 1047-1057.

2. Saitoh, T., et al., Two-Dimensional Model for Twin-Roll Continuous Casting, Metallurgical Transactions B, Vol. 20B(6), 1989, pp. 381-390.

3. Fujita, Y., et al., Solidification and Roll-Bonding of Shells in Twin-Roll Casting Process, Iron and Steel Institute of Japan International, Vol. 29(6), 1989, pp. 495-502.

4. Shiomi, M., Mori, K., and Osakada, K., Finite Element and Physical Simulations of NonSteady State Metal Flow and Temperature Distribution in Twin Roll Strip Casting, Modeling of Casting, Welding, and Advanced Solidification Processes Proceedings, Vol. 7, 1995, pp. 793-800.

5. Yukumoto, M., and Yamane, H., Thin Strip Casting of Ni-Base Alloys by Twin Roll Process, 78th Steelmaking Conference Proceedings, Vol. 78, 1995, pp. 19-22.

6. Getselev, Z. N., Method of Forming Ingot in a Process of Continuous and Semi-Continuous Casting of Metals, U.S. Patent 4014379, March 29, 1977.

7. Olson, E. A., Method and Apparatus for Excluding Molten Metal from Escaping from or Penetrating into Openings or Cavities, U.S. Patent 4020890, May 3, 1977.

8. Lewis, B.G., Electromagnetic Shaping of Thin Semiconductor Ribbon Strip Cast onto a Chilled Block, U.S. Patent 4562878, January 7, 1986.

9. Lowry, H. R., et al., Continuous Metal Casting Apparatus, U.S. Patent 4662431, May $5,1987$.

10. Tacke, K. H., and Schwerdtfeger, K., Stirring Velocities in Continuously Cast Round Billets as Induced by Rotating Electromagnetic Fields, Stahl \& Eisen, Vol. 99(1), 1979, pp. 7-12.

11. Spitzer, K. H., Dubke, M., and Schwerdtfeger, K., Rotational Electromagnetic Stirring in Continuous Casting of Round Strands, Metallurgical Transactions, Vol. 17B, 1986, pp. 119131.

12. Partinen, J. K., Saluja, N., Szekely, J., and Kirtley, J., Experimental and Computational Investigation of Rotary Electromagnetic Stirring in a Woods Metal System, ISIJ Int'l, Vol. 
$34(9), 1994$, pp. $707-714$.

13. Beitelman, L. and Mulcahy, J. A., Flow Control in the Meniscus of Continuous Casting Mold with an Auxiliary A.C. Magnetic Fields, Int'l Symposium on Electromagnetic Processing of Materials, EPM'94, Nagoya, Japan, 1994, The Iron and Steel Institute of Japan, pp. 235241.

14. Chang, F. C., Hull. J. R., and Beitelman. L., Simulation of Fluid Flow Induced by Opposing AC Magnetic Fields in a Continuous Casting Mold, 13th Process Technology Conference Proceedings, Iron and Steel Society, Vol. 13, 1995, pp. 79-88.

15. Saucedo, I. G., and Blazek, K. E., Development of an Electromagnetic Edge Dam (EMD) for Twin Roll Casting, METEC-94, pp. 457-462.

16. Blazek, K. E., Gerber, H. G., and Saucedo, I. G., Application of Alternating Magnetic Fields for Edge Containment in Strip Casting, Int'l Symposium on Electromagnetic Processing of Materials, EPM'94, Nagoya, Japan, 1994, The Iron and Steel Institute of Japan, pp. 197-202.

17. Domanus, H. M., Schmitt, R. C., and Ahuja, S., User's Guide for the Casting Process Simulator Software CaPS-2D, Version 1.0, Argonne National Laboratory Report ANL93/14, July 1993.

18. Bird, R. B., Stewart, W. E., and Lightfoot, E. N., Transport Phenomena, John Wiley \& Sons, Inc., New York, 1966.

19. Tallback, G., Kollberg, S., and Hackl, H., Simulations of EMBR Influence on Fluid Flow in Slabs, 17th Advanced Technology Symposium, Phoenix, Arizona, February 13-16, 1994.

20. Chang, F. C., Bottoni, M., and Sha, W. T., Development and Validation of the k- $\varepsilon$ TwoEquation Turbulence Model and the Six-Equation Anisotropic Turbulence Model in the COMMIX-1C/ATM, Argonne National Laboratory Report ANL/ATHRP -44, January 1992.

\section{NOMENCLATURE}

B Magnetic flux density (T)

C $\quad(=9.0)$ Constant characterizing the roughness of a boundary surface

$c_{\mu} \quad(=0.09)$ Constant 


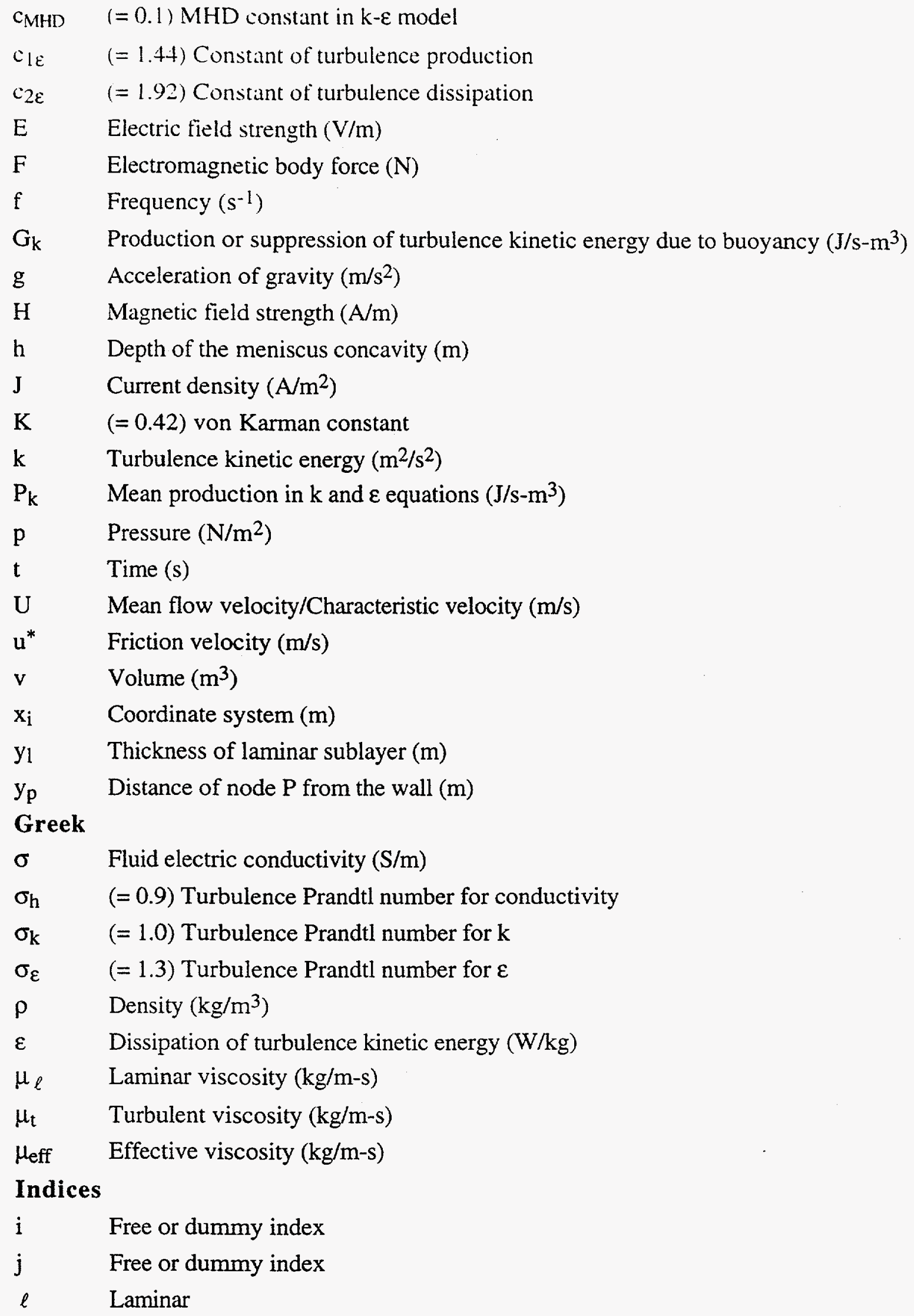

\section{Indices}

i Free or dummy index

j Free or dummy index

$\ell \quad$ Laminar 
Liquid Metal

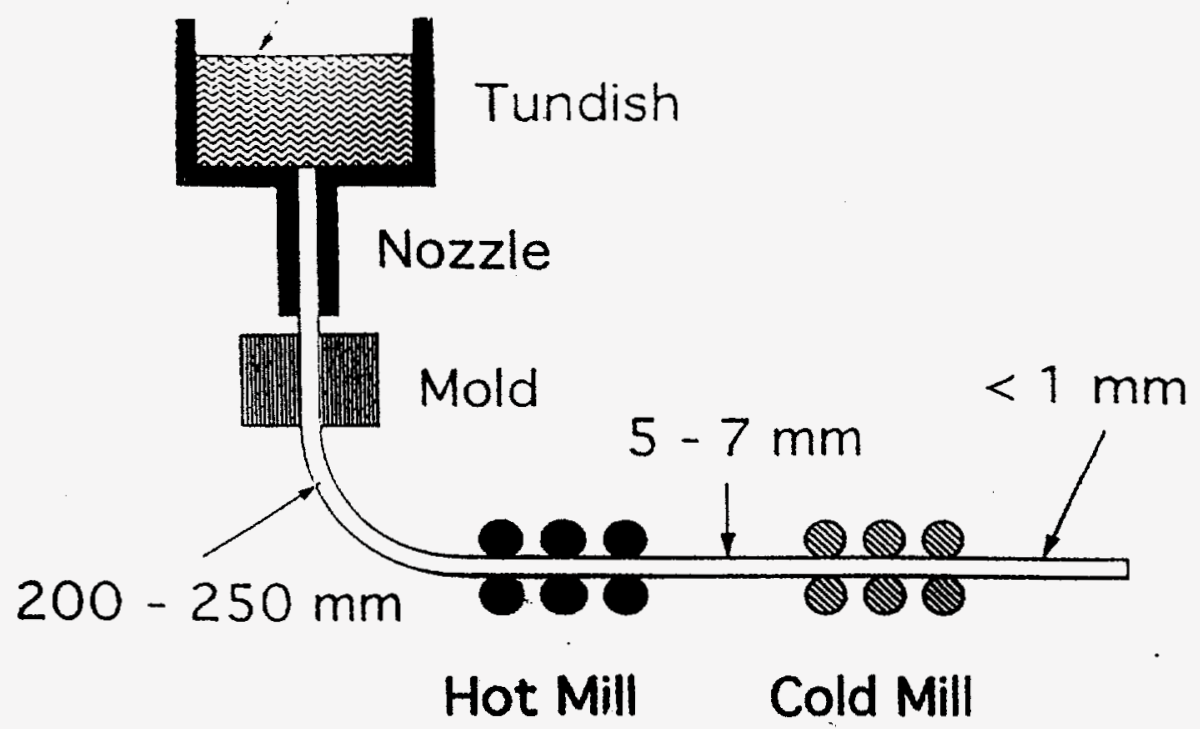

Figure 1. Configuration of conventional slab casting

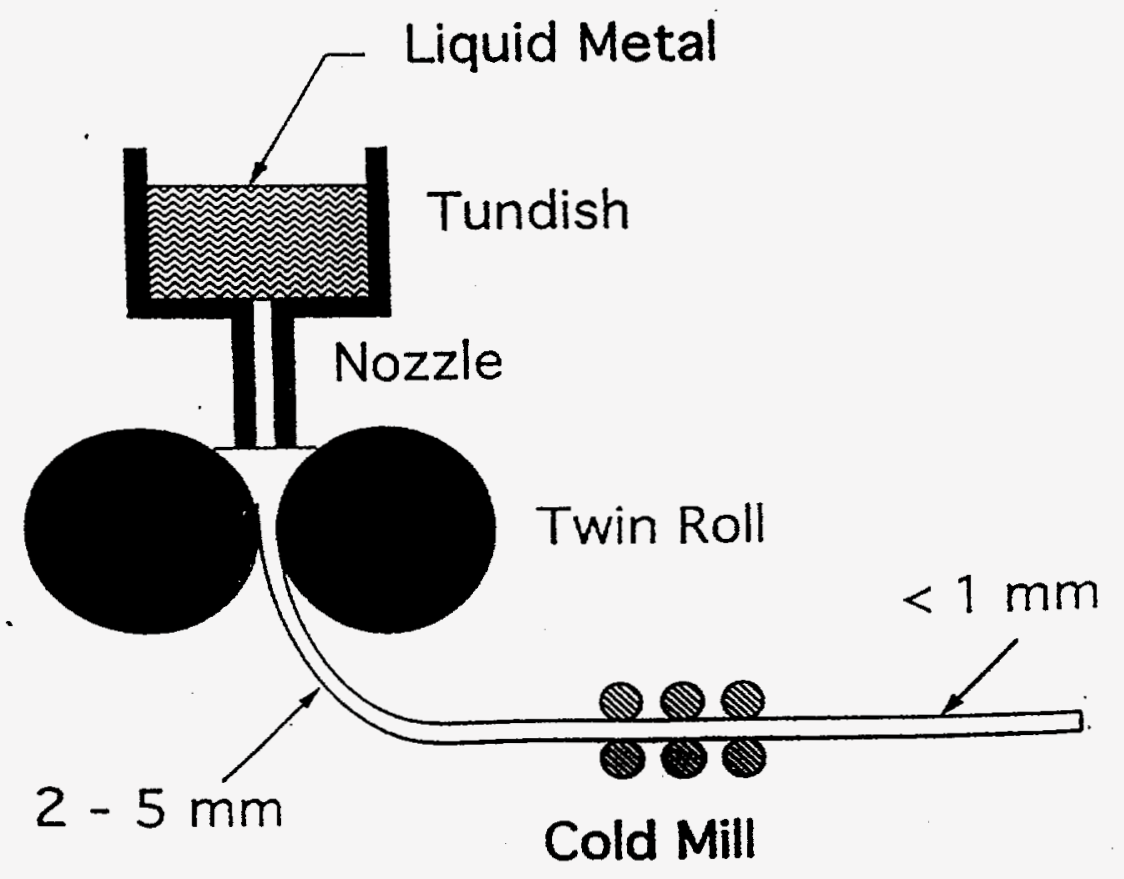

Figure 2. Configuration of twin-roll casting with ceramic solid dam 


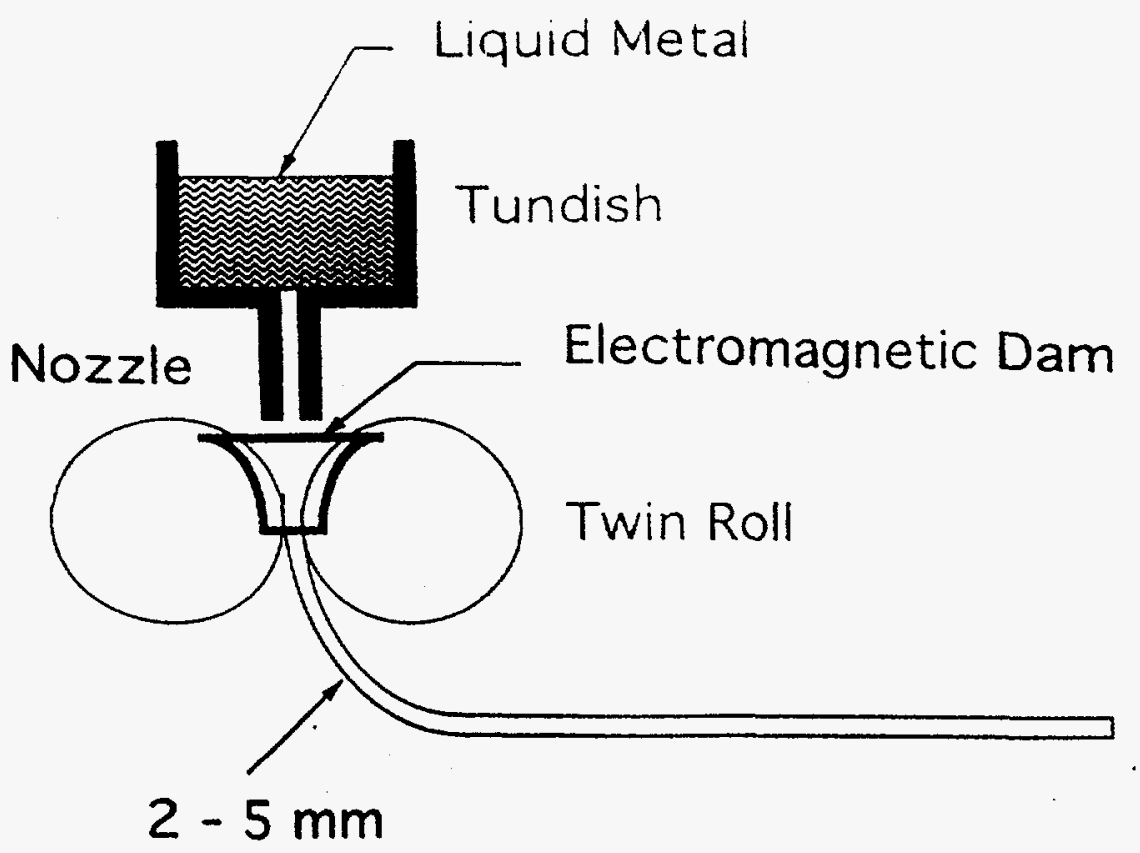

Figure 3. Configuration of twin-roll casting with EMD

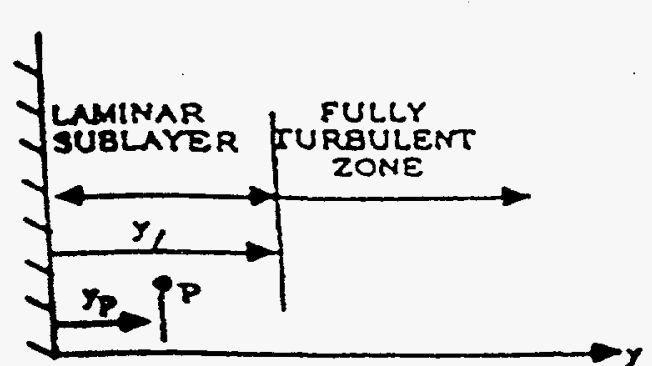

(a)

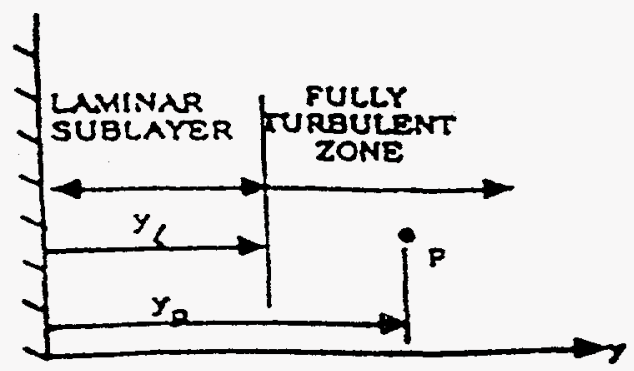

(b)

Figure 4. Schematic representation of two-layer wall function model: (a) $y_{p}<y_{t}$ and (b) $y_{p}>y_{1}$ 


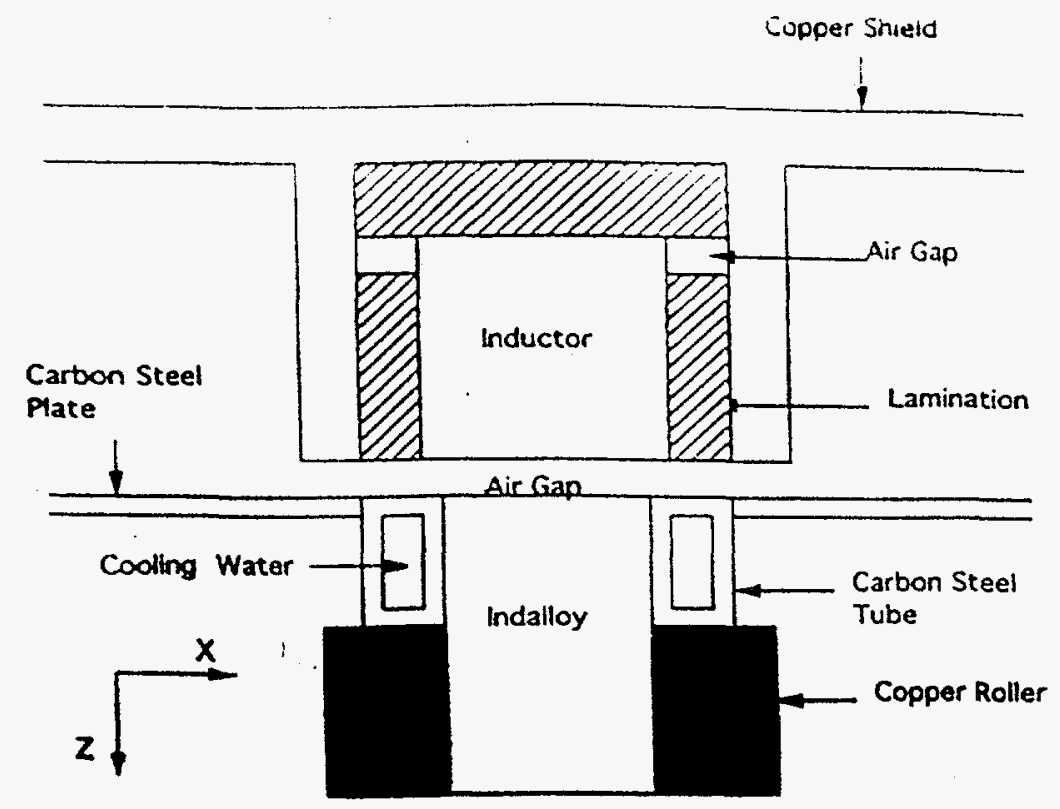

Figure 5. Schematic arrangement of EMD in twin-roll casting

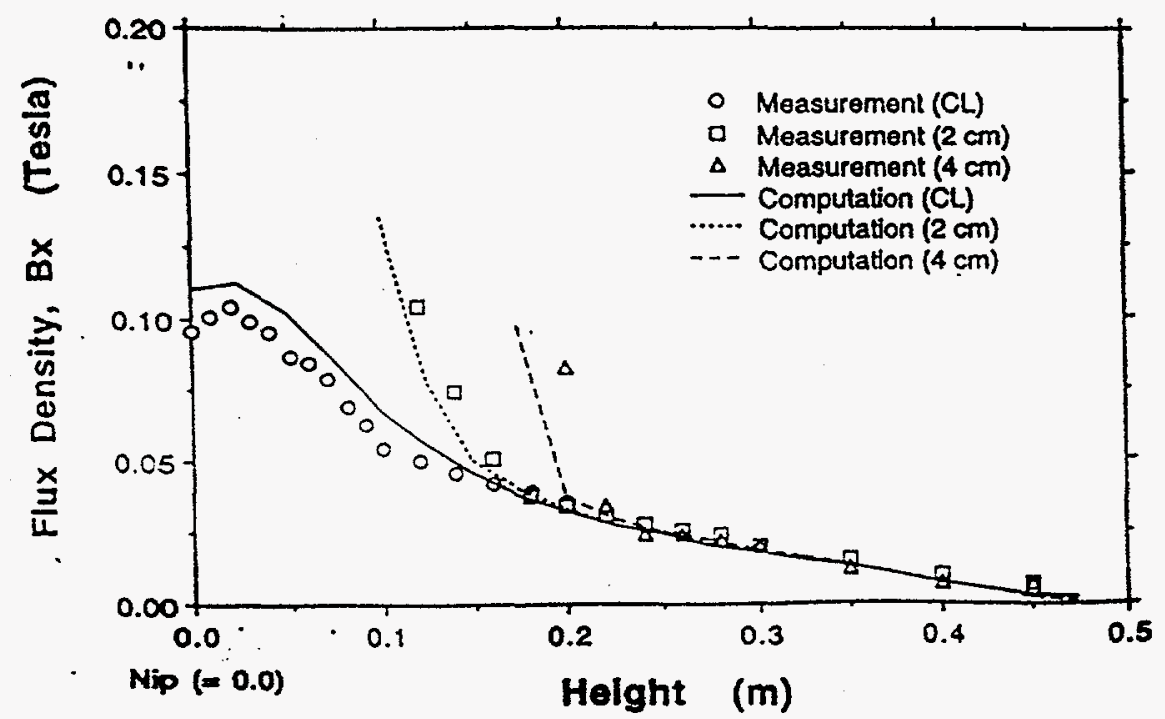

Figure 6. Magnetic flux density $(\mathrm{Bx})$ vertical profile in air gap for EMD 


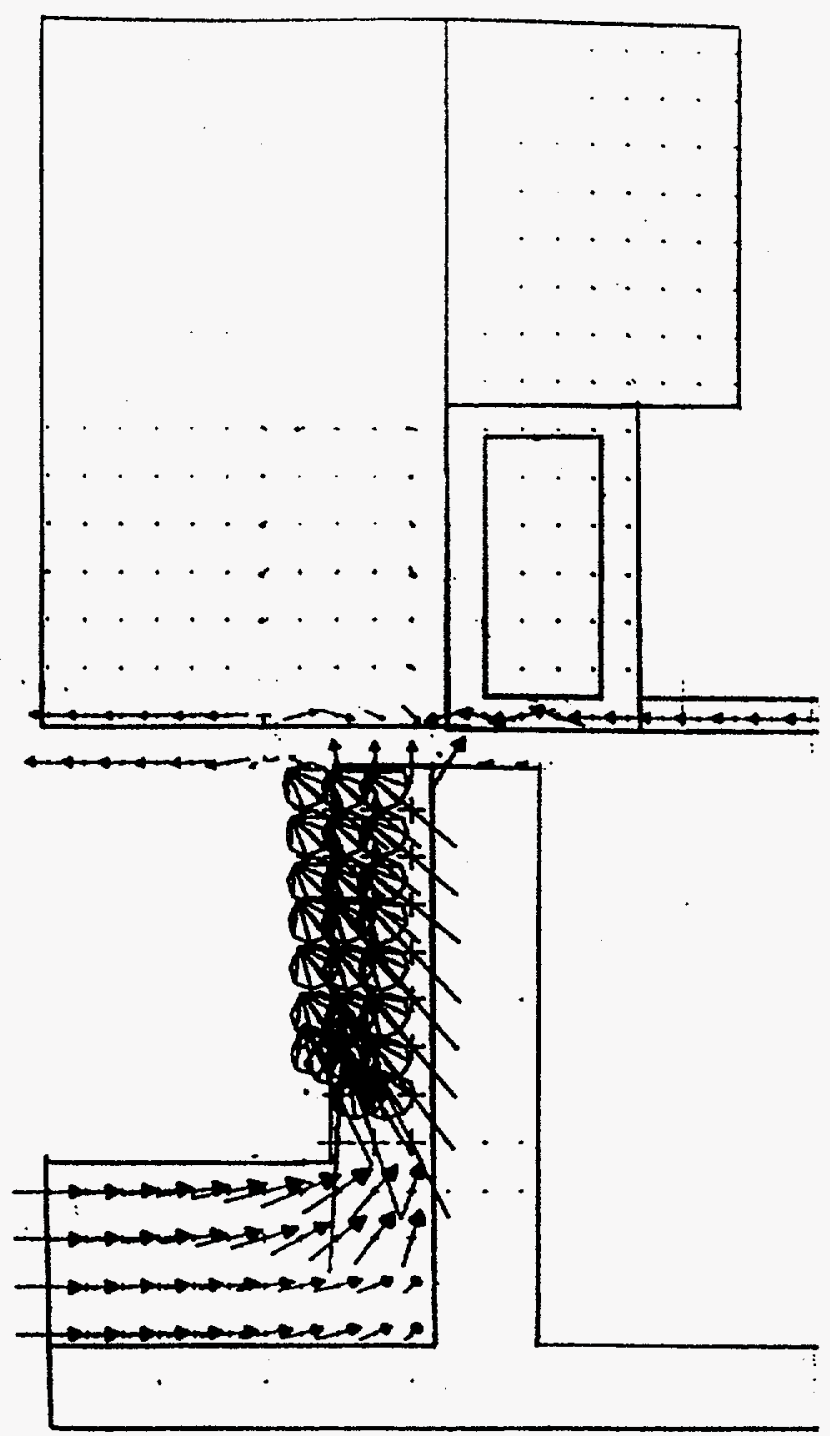

Figure 7. Distribution of magnetic flux density vector at cut plane $(15 \mathrm{~cm}$ above the nip) of EMD in twin-roll casting 


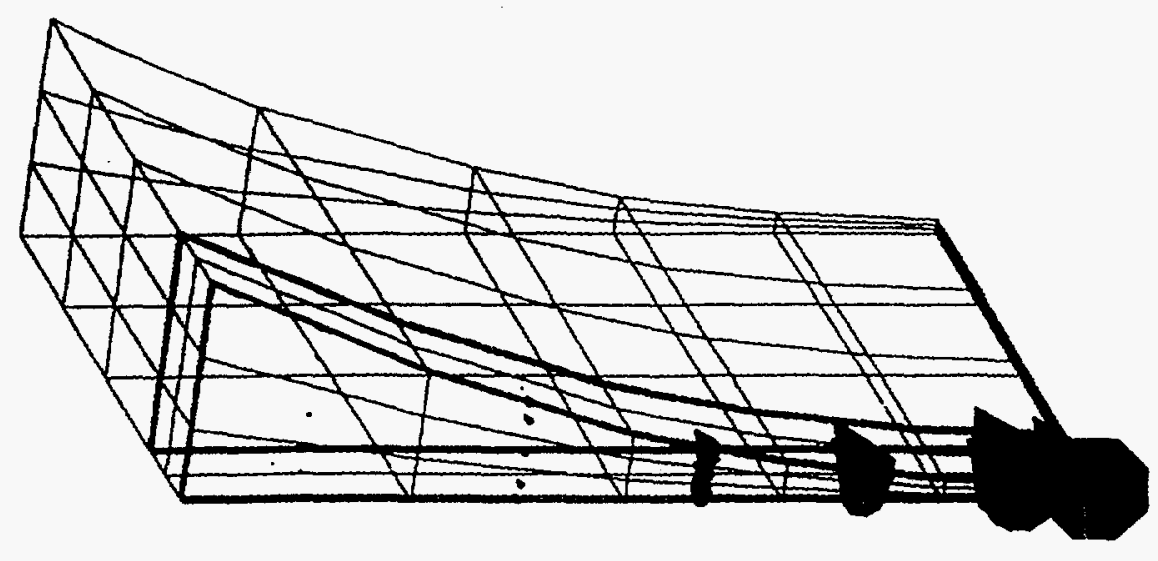

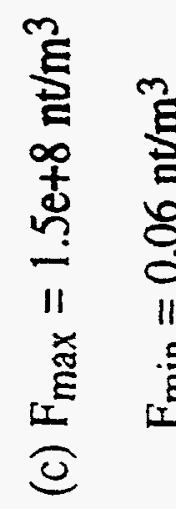

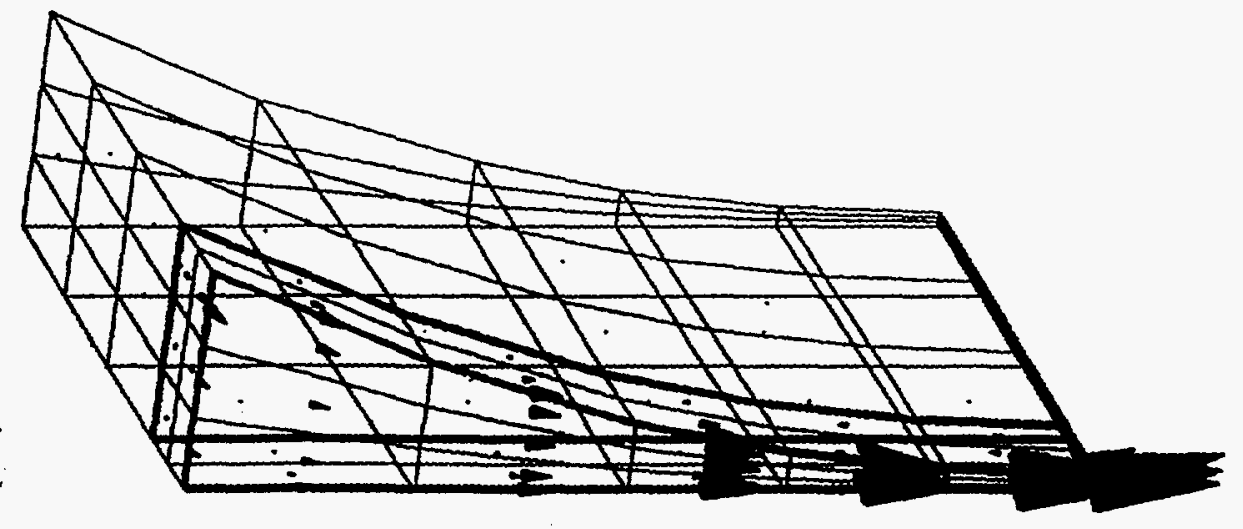

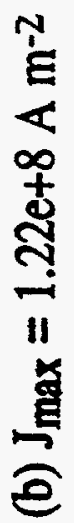
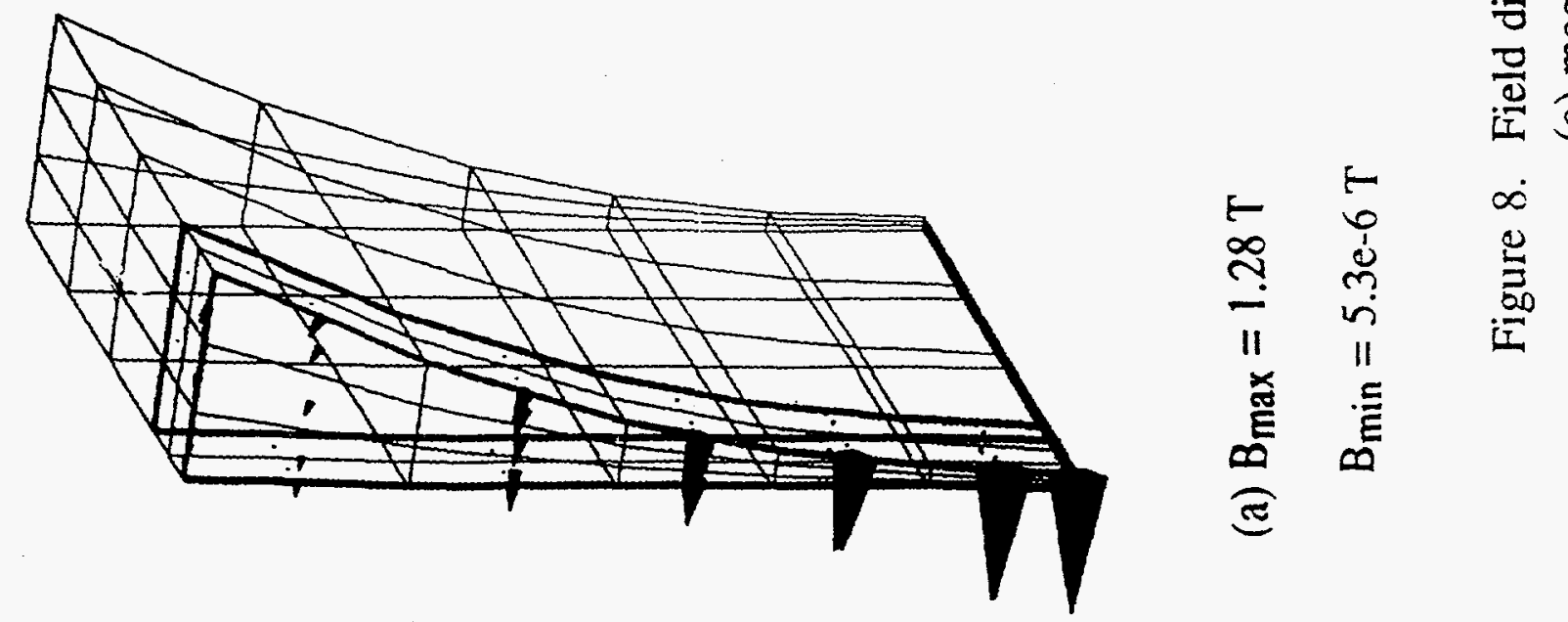


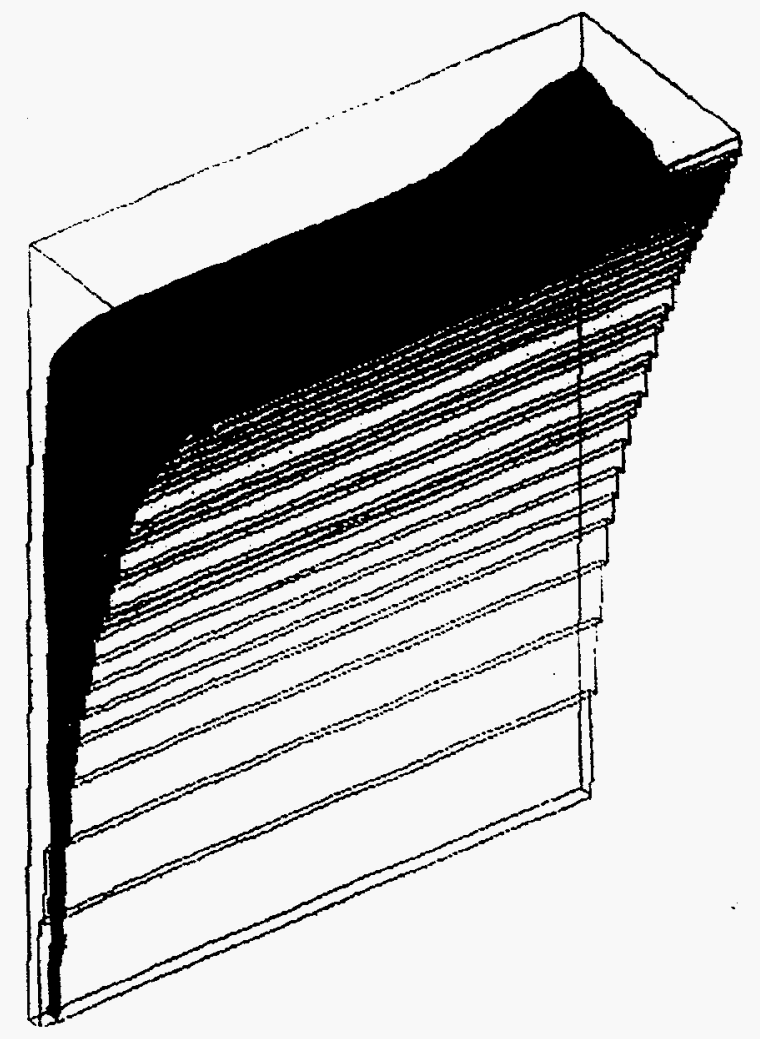

Figure 9. Free surface of liquid Indalloy in twin-roll casting with EMD

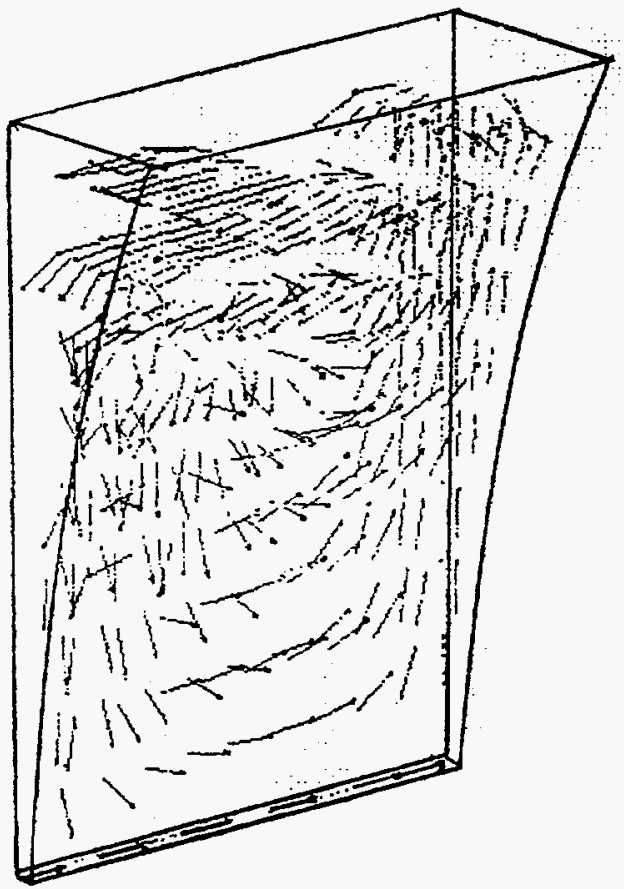

Figure 10. Velocity profile of liquid Indalloy in twin-roll casting with EMD 


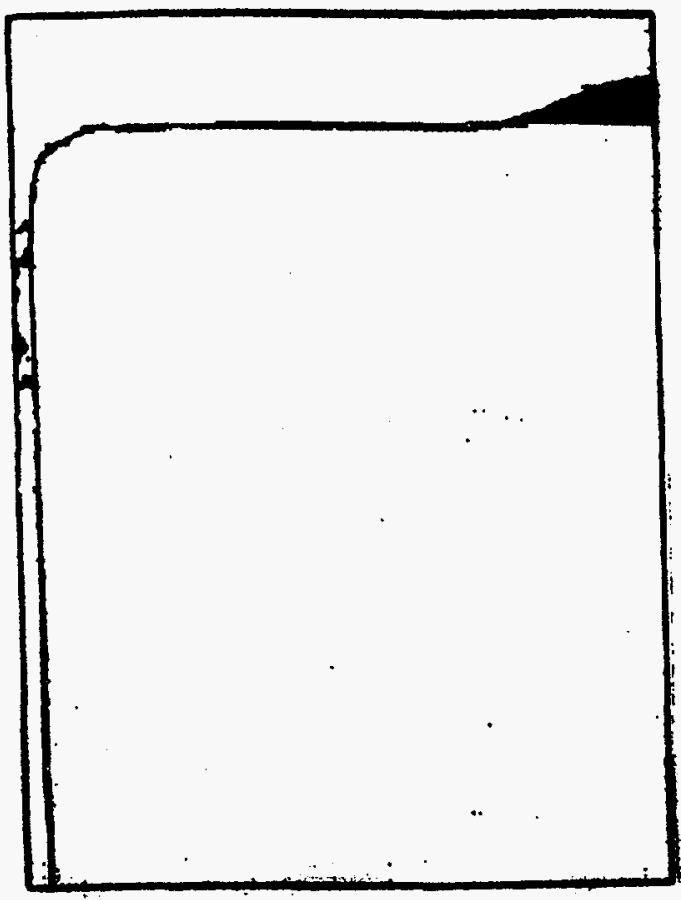

(a)

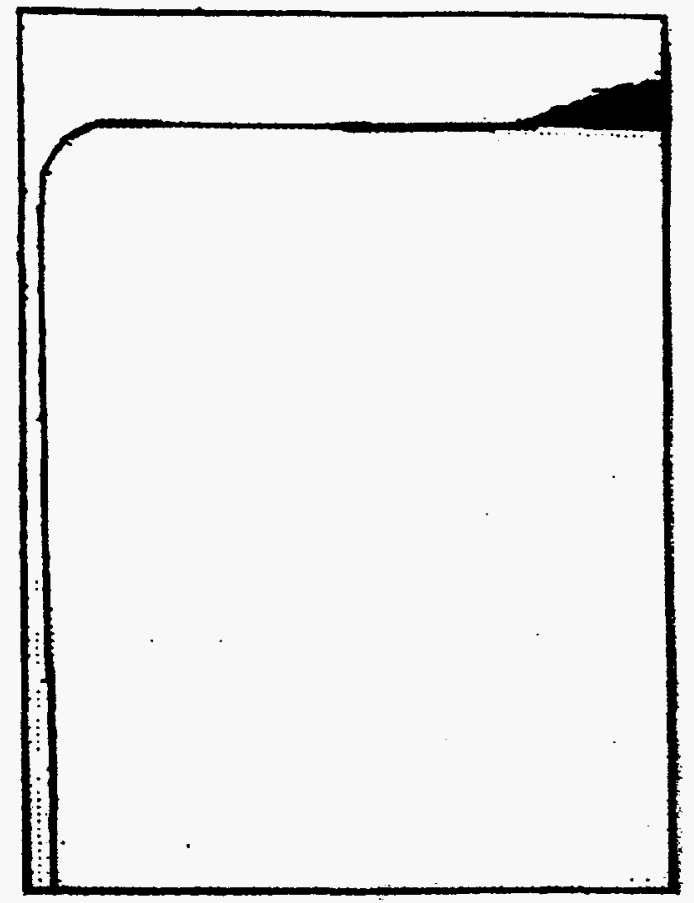

(b)

Figure 11. Liquid metal (Indalloy) confinement for operating currents (a) $\mathrm{I}=13 \mathrm{kA}, \mathrm{f}=4.4 \mathrm{kHz}$ and (b) $\mathrm{I}=18 \mathrm{kA}, \mathrm{f}=4.4 \mathrm{kHz}$

\section{DISCLAIMER}

This report was prepared as an account of work sponsored by an agency of the United States Government. Neither the United States Government nor any agency thereof, nor any of their employees, makes any warranty, express or implied, or assumes any legal liability or responsibility for the accuracy, completeness, or usefulness of any information, apparatus, product, or process disclosed, or represents that its use would not infringe privately owned rights. Reference herein to any specific commercial product, process, or service by trade name, trademark, manufacturer, or otherwise does not necessarily constitute or imply its endorsement, recommendation, or favoring by the United States Government or any agency thereof. The views and opinions of authors expressed herein do not necessarily state or reflect those of the United States Government or any agency thereof. 